Bull. Fac. Agric, Cairo Univ., 70:141-151 (2019).

\title{
ECONOMIC EVALUATION FOR THE EFFECT OF IRRIGATION RATES ON SOME BREAD WHEAT GENOTYPES
}

(Received: 5.5.2019)

\author{
By \\ Sahar A. I. Ibrahem, Wafaa. A. M. Eid and Y. I. El-Gohary* \\ Center Laboratory for Design \&Stat. Analysis Research, and * Wheat Research Secncse, Field Crop \\ Research, Agricultural Research Center, Giza, Egypt.
}

\begin{abstract}
The wheat crop is considered one of the main grain crops and one of the most important strategic crops in the Egyptian diet. The study aimed to evaluate the effect of irrigation rates on some wheat genotypes using data of a field experiment conducted in the Agricultural Research Station of Itay AlBaroud, Beheira Governorate during 2016/2017-2017/2018 seasons. Three irrigation rates (2, 3 and 4 irrigations after planting) were applied to six wheat genotypes (Egypt 2, Gemmiza 11, Egypt 1, Shandaweal 1, strain 1, strain 2). By studying the statistical relationship between the area, in thousand feddans, and time factor, it was shown that the area significantly increased annually by 52.84 thousand feddans. Also, the productivity increased by $0.04 \mathrm{ardab} / \mathrm{fed}$ and this increase was not significant. meanwhile, the total production significantly increased annually by 1094.14 thousand ardb. This increase was due to the increase in the cultivated area. The results indicated that the increase in the farm price, productivity costs, total revenue, net revenue per feddan is estimated at 26.97 pound/fed, 240,48 pound/fed, 611.26 pound/fed, 370.79 pounds/fed, respectively. It was also found that the return of the invested pound is considered an economic gain for the farmer during the period (2002-2017). The results revealed that the second irrigation treatment ( 3 irrigations after planting) achieved the highest feddan productivity, highest revenue, highest net return and highest value of the invested pound. Moreover, the wheat cultivar Egypt 1 gave the highest productivity, highest revenue, the highest net return and highest return of the invested pound in the first season, while strain 1 achieved the highest productivity, the highest revenue, the highest net return and the highest return of the invested pound in the second season.
\end{abstract}

Keywords: Bread wheat-irrigation rates- economic evaluation.

$$
\begin{aligned}
& \text { التقييم الاقتصادي لمعلات ري بعض التراكيب الوراثية لمحصول قمح الخبز } \\
& \text { سحر عبد السلام إبراهيم - وفاء أبو بكر محمد عيد - ياسر احمد الجوهري* } \\
& \text { المعمل المركزي لبحوث التصميم و التحليل الإحصائي - و*قسم بحوث القمح- معهد بحوث المحاصيل الحقلية }
\end{aligned}
$$

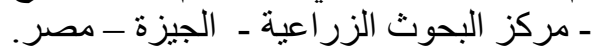

$$
\begin{aligned}
& \text { ملخص } \\
& \text { يعتبر محصول القمح احد محاصيل الحبوب الرئيسية بل احد أهم المحاصيل الإستر اتيجية في النمط الغذائي المصري. }
\end{aligned}
$$

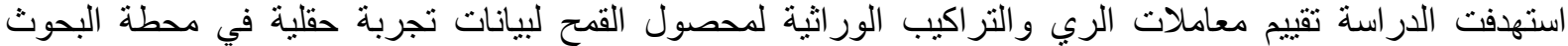

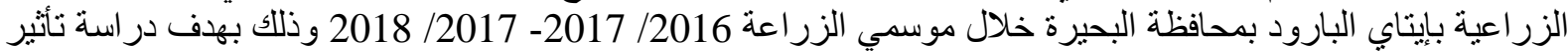

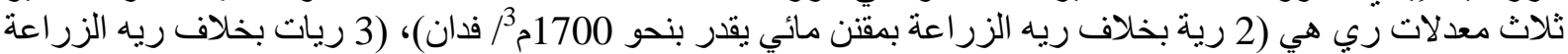

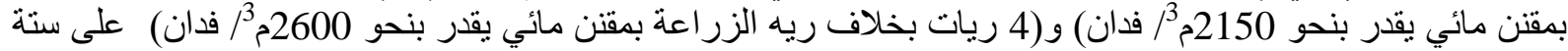

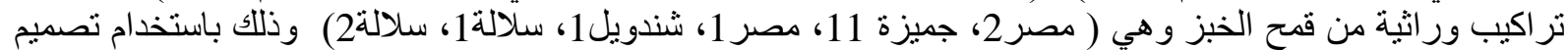

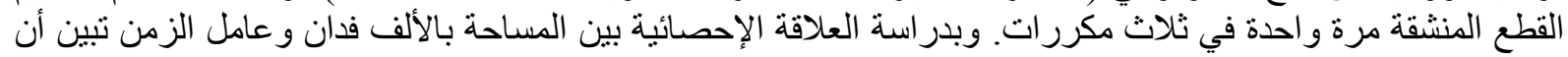


المساحة تتز ايد سنويا بنحو 52.84 ألف فدان و هذه الزيادة معنوية كما تبين أيضا زيادة الإنتاجية بنحو 0.04 إردب/فئفان إنبان

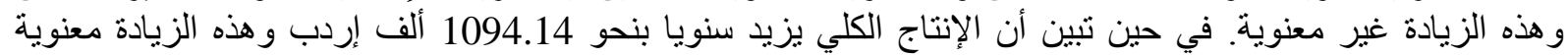

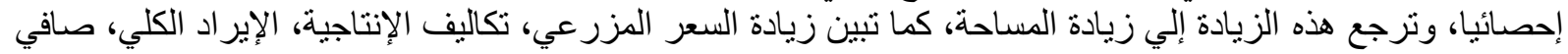

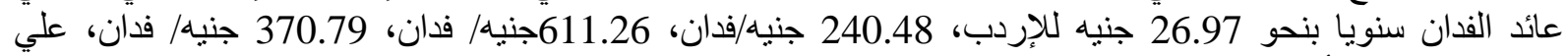

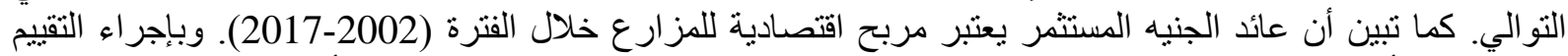

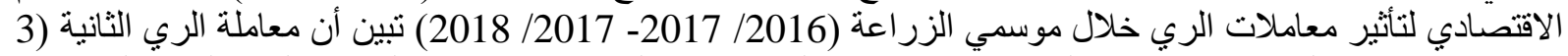

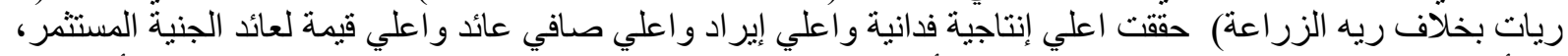

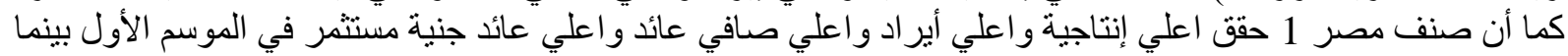

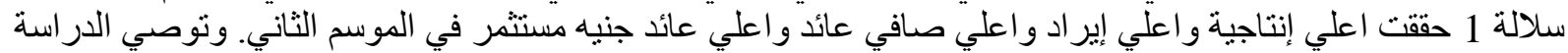

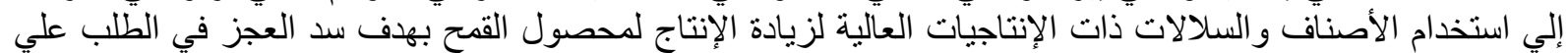

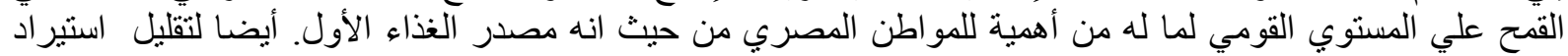

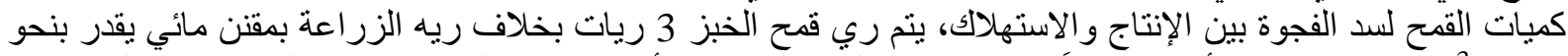

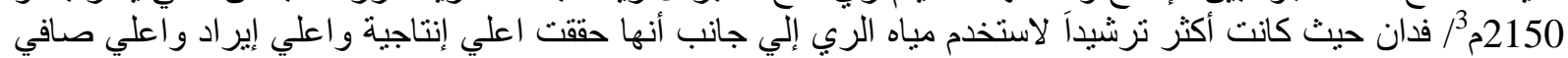
عائد واعلي قيمة لعائد الجنية المستثر. فئر.

إنتاجيه لمحصول القمح تعتبر احد الحلول التي تعالج بها نقص الإنتاج في ظل ندرة المياه

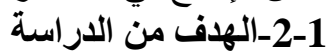

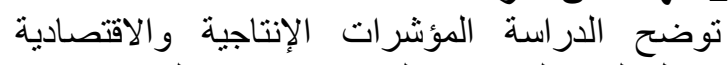

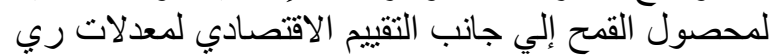

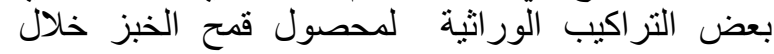

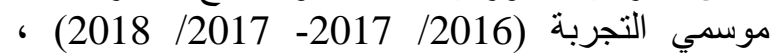
و التقييم الاقتصادي لتأثير التراكيب الوراثية لقمح الخبز

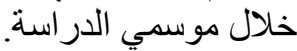

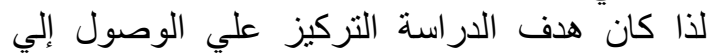

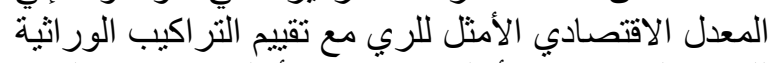

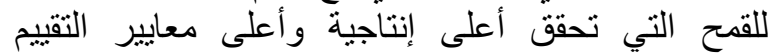

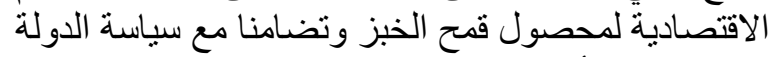
في التوسع الر أسي عن طريق زئ اليادة الإنتاجية الفدانية.

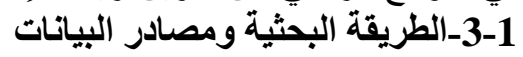

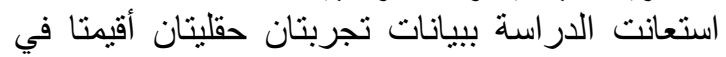
محطة البحوث الزراعية بايتاي البارود بمحافظة البحيرة خلال موسمي الزراعة 2016/ 2017- 2017/ وذللك بهدف دراسة تأثير ثلاث معدلات ري هي هي (20) رية

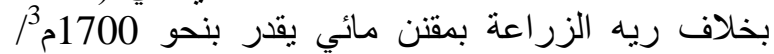

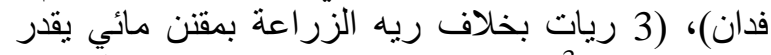

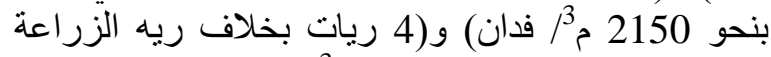

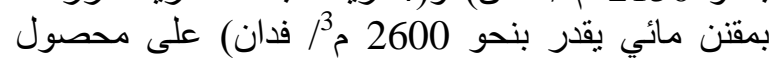

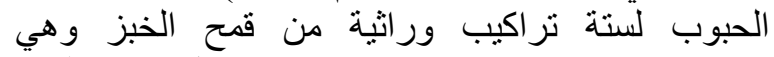

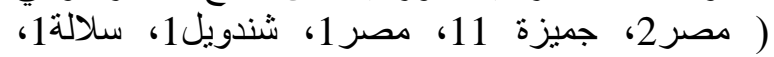
سلالة2) و وذلك باستخدام تصميم القطع المنشقة مرة و احدة

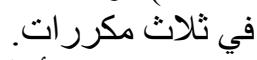

تم استخدام أسلوب تحليل التباين في اتجاهين لدراسة

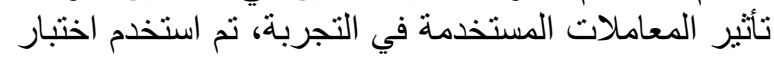

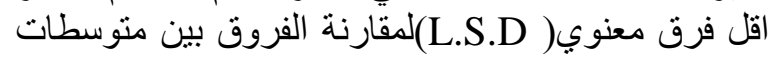

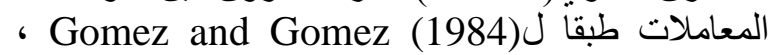
Snedecor and Cochran ( 1988)

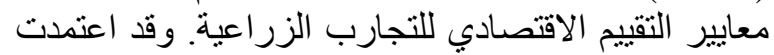

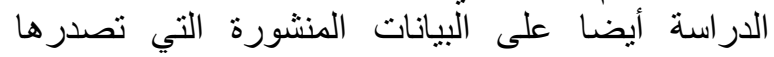
الجهات الرسمية لقطاع الثئون الاقتصادية بوزية لتوزارة

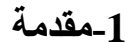

يعتبر محصول القمح احد محاصيل الحبوب الرئيسية بل احد أهم المحاصيل الإستراتيجية في النمط الغذائي الهئي

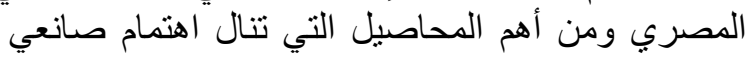

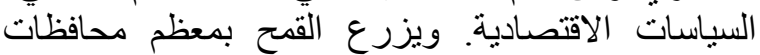

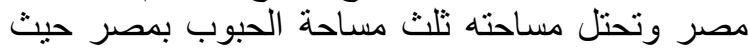

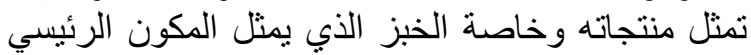

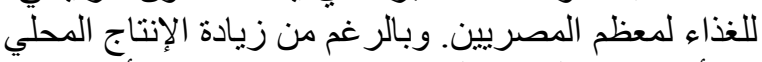

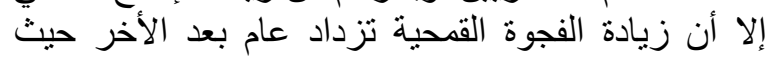

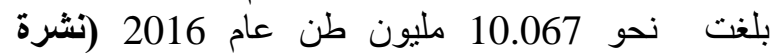
الميزان الغذائي) وتراجعت معدلات الاكتفاء الذاتي من عن من

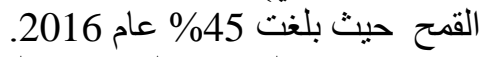
تهذف السياسة الزراعية المصرية إلى الى تشجية

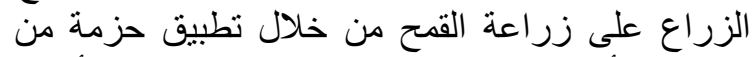

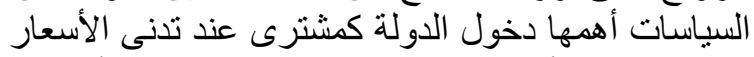

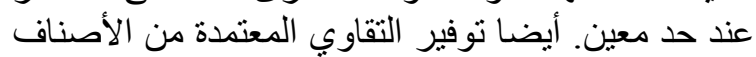

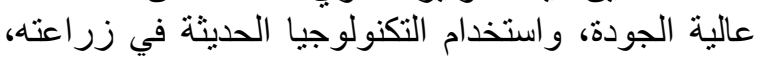

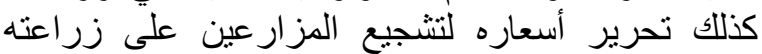

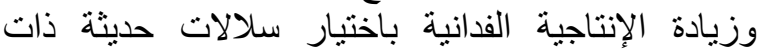

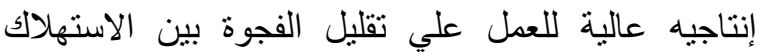
والإنتاج و أيضا المساهمة في تقليل كمية الواردات من لإن

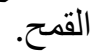

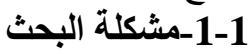

علي الرغم من زيادة البحث المساحة المزروعة والإنتاجية

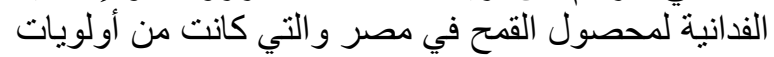

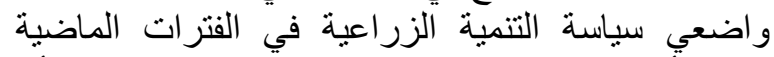

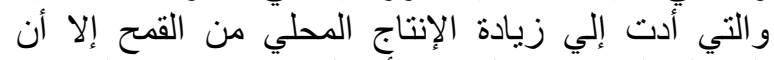

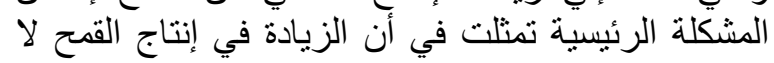

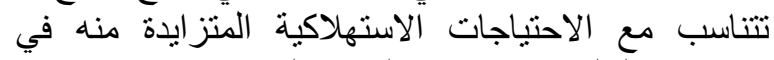

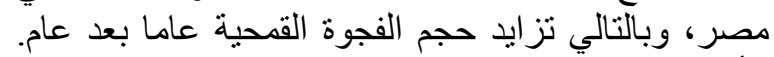

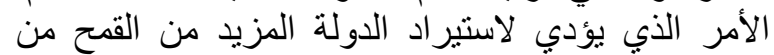

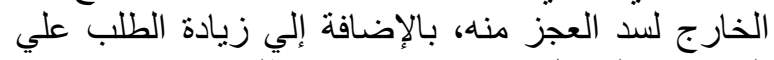
المياه مع الدخول في ندرنها مما بتطلب ترشئ الإنيد استخدام

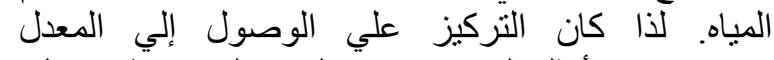
الاقتصادي الأمثل لكميات مياه الريز التي تعطي العي الئي 
الدراسة كانت أعلي منها في سنة الأساس، فيما عدا عام 2006 و عام 2010 نرجع هذه الزيادة في الإنتاجية و غالباً إلي ارتفاع مستوي التكنولوجيا المستخدمة في الإنتاج الإنتاجية

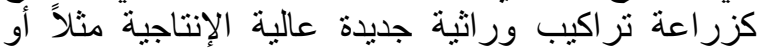

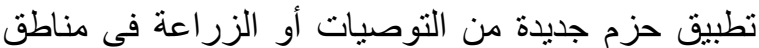

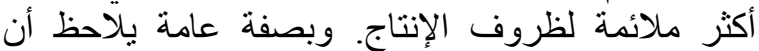

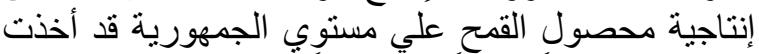

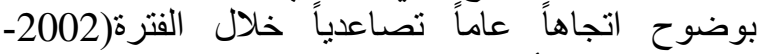
2017). يتبين أن العلاقة بين إنتاجية محصول القاعل القدح بالإردب/ فدان وعامل الزمن علي مستوي الجمهورية

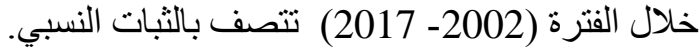

-3-2 - الإنتاج الكلي

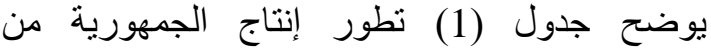

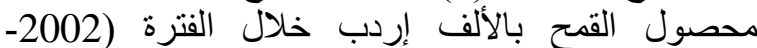

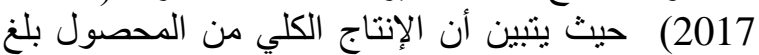

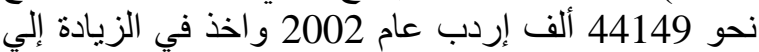

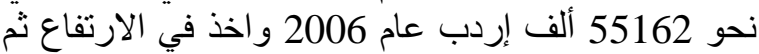

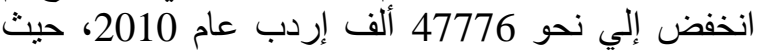
أخذ في الزيادة المستمرة بصورة تدريجية إلي أن بلغ النغ النغ

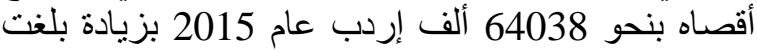

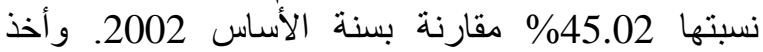
الإنتاج بعد ذللك في الانخفاض التدريجي إلي أن بلغ نحو

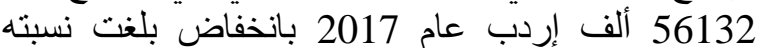

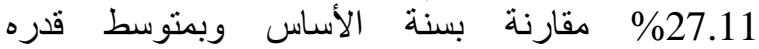
54745ألف إردب خلال الفترة (2002- 2017)

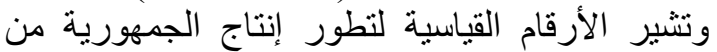
محصول القمح خلال فترة الدراسة إلي ارتفاع التاع الإنتاج

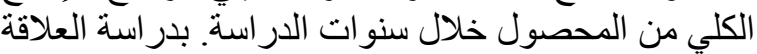

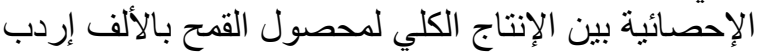

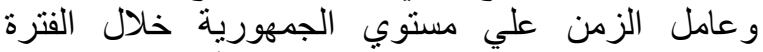

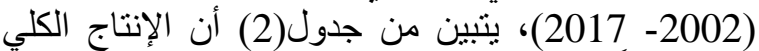

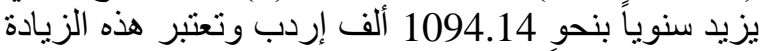

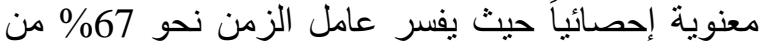
إجمالي التغيرات في الإنتاج الكلي للمحصول الزمن خلال فترة

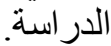

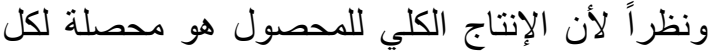

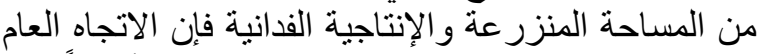

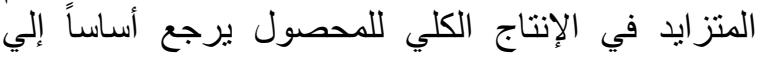

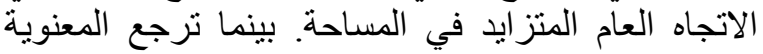

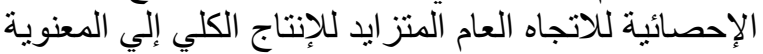

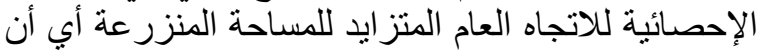

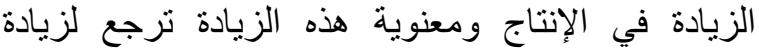
المساحة والإنتاجية الفدانية.

\section{3-المؤشر ات الاقتصادية لمحصول القمح}

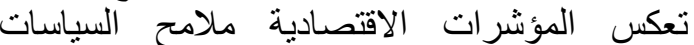

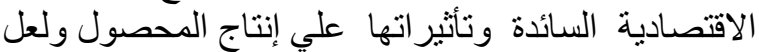

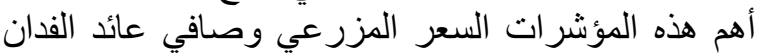

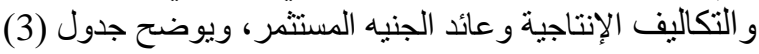
تطور المؤشرات الاقتصادية خلال الفترة (2002- 2017)
الزر اعة، إلي جانب الاستعانة ببعض الدراسات و الأبحاث

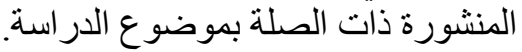

\section{2- المؤشرات الإتتاجية لمحصول القمح}

ترجع أهية دراسة المؤشرات الإنتاجية لمحصول المصنية

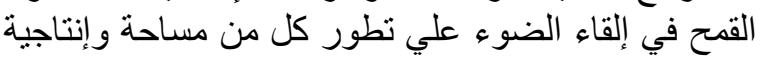
و إنتاج المحصول عبر فترة زمنية لفية محددة لتعكس مر احل

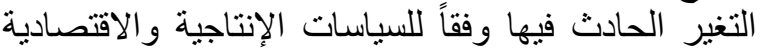
السائدة. ويوضح جدول (1) نطور أهم المؤشرات الإنتانية الإنتاجية

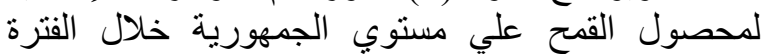
(2002- 2017) والتي تشمل كل من المساحة المنزر عة الإلة بالألف فدان والإنتاجية الفدانية بالإردب والإن الإنتاج الكلي الإني

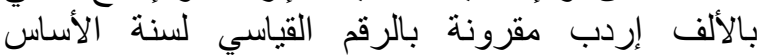

- 1-2 - المساحة المنزرعة يوضح جدول (1) تطور المساحة المنزر عة بهة بمحصول القمح بالألف فدان علي مستوي الجمهورية خلال الفئ الفترة

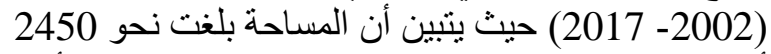

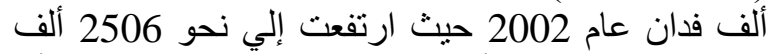

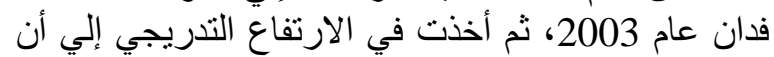

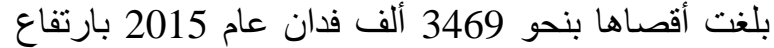

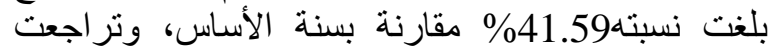
المساحة بعد ذلك إلي أن بلغت نحو 2922 ألف فدان عان عام

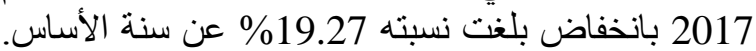
وذللك خلال ستة عشر سنه بمنوسط قدره

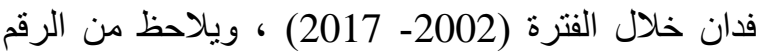
القياسي لنطور المساحة المنزرعة بالقال القمح أن المساحة

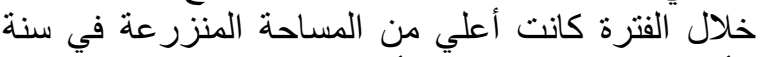

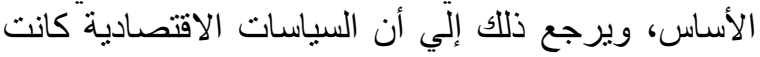
عامل مؤثر في زيادة المساحة خلال الفترة الفال (2002-

2017

بدراسة العلاقة الإحصائية بين مساحة القمح بالألف فدان و عامل الزمن علي مستوي الجمهورية خلال الفية الفترة

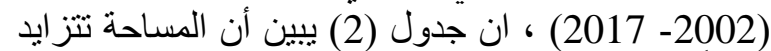

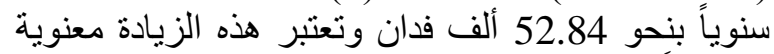

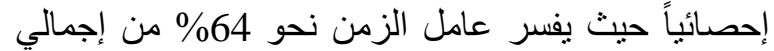
التغيرات في مساحة المحصول خلال فترة الدراسة. 2-2-2 الإنتاجية (لقدانية

يشير جدول (1) إلي نطور الإنتاجية الفدانية لمحصول

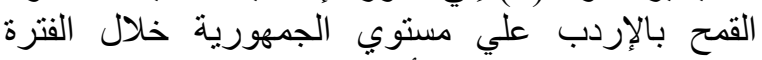
(2002- 2017) ويتبين أن الإنتاجية بلغت نحو 18.02

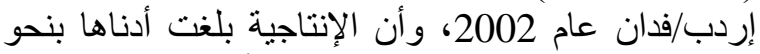

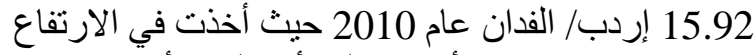
تارة والانخفاض تارة أخرى إلي أن بلغت أقتصاها بندو الخداع

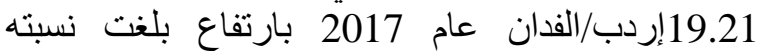
6.60\% مقارنة بسنة الأساس 2002، بمتوسط قدره 18.19 إردب/ الفدان خلال فترة الدراسة (2002-

وبجدر الإشارة إلي أن الرقم القياسي لتطور إنتاجية محصول القمح يثير إلي أن الإنتاجية خلال سنوات النيات 
جدول(1): تطور المؤشرات الإنتاجية لمحصول القمح خلال الفترة (2002- 2017).

\begin{tabular}{|c|c|c|c|c|c|c|}
\hline القياسي & بالألف إردب الإنتاج & الرقم القياسي & الإلإزباجة الإبدان & الرقم القياسي & بالألف فدانة & السنة \\
\hline 100 & 44149 & 100 & 18.02 & 100 & 2450 & 2002 \\
\hline 103.32 & 45634 & 101.05 & 18.21 & 102.29 & 2506 & 2003 \\
\hline 108.35 & 47854 & 101.94 & 18.37 & 106.33 & 2605 & 2004 \\
\hline 122.88 & 54267 & 100.89 & 18.18 & 121.84 & 2985 & 2005 \\
\hline 124.90 & 55152 & 99.89 & 18.00 & 125.06 & 3064 & 2006 \\
\hline 111.38 & 49214 & 100.55 & 18.12 & 110.86 & 2716 & 2007 \\
\hline 120.41 & 53173 & 101.05 & 18.21 & 119.18 & 2920 & 2008 \\
\hline 128.65 & 56835 & 100.22 & 18.06 & 128.45 & 3147 & 2009 \\
\hline 108.21 & 47776 & 88.35 & 15.92 & 122.49 & 3001 & 2010 \\
\hline 126.35 & 55797 & 101.55 & 18.3 & 124.45 & 3049 & 2011 \\
\hline 132.76 & 58637 & 102.94 & 18.55 & 129.02 & 3161 & 2012 \\
\hline 142.80 & 63067 & 103.61 & 18.67 & 137.88 & 3378 & 2013 \\
\hline 140.07 & 61854 & 101.17 & 18.23 & 138.49 & 3393 & 2014 \\
\hline 145.02 & 64038 & 102.44 & 18.46 & 141.59 & 3469 & 2015 \\
\hline 141.02 & 62265 & 103.05 & 18.57 & 136.86 & 3353 & 2016 \\
\hline 127.11 & 56132 & 106.60 & 19.21 & 119.27 & 2922 & 2017 \\
\hline 123.95 & 54745 & 100.96 & 18.19 & 122.75 & 3007.44 & المتوسط \\
\hline
\end{tabular}

المصـدر: وزارة الزر اعـة واستصـلاح الأر اضــ، قطـاع الثـئون الاقتصـادية، الإدارة المركزيـة للاقتصـاد الزر اعي، نشـرة الإحصـاءات الزراعية، أعداد مختلفة.

جدول (2): معادلات الاتجاه الزمني العام لتطور أهم المؤشرات الإتتاجية والاقتصادية لمحصول القمح علي مستوي الجمهورية خلال الفترة (2002-

\begin{tabular}{|c|c|c|c|c|}
\hline$R^{2}$ & $\boldsymbol{R}$ & المعادلة & المؤشر & رقم المعادلة \\
\hline 0.64 & 0.80 & $\hat{Y}_{i}=\underset{(24.80)^{* *}}{2558} \underset{(4.95)^{* *}}{52.84} X_{i}$ & المساحة بالألف فدان & 1 \\
\hline 0.67 & 0.82 & $\hat{Y}_{i}=\underset{(22.74)^{* * *}}{45444} \underset{(5.29)^{* * *}}{1094} X_{i}$ & الإنتاج بالألف/ إردب & 2 \\
\hline 0.88 & 0.94 & $\hat{Y}_{i}=\underset{(2.55)^{*}}{64.50}+\underset{(10.32)^{* * *}}{26.97} X_{i}$ & السعر المزرعي جنيه/ الإردب بالأسعار & 3 \\
\hline 0.95 & 0.97 & $\hat{Y}_{i}=\underset{(1.77)^{*}}{255.45}+\underset{(16.14)^{* * *}}{240.48} X_{i}$ & التكاليف الكلية بالجنيه بالأسعار الجارية & 4 \\
\hline 0.88 & 0.94 & $\hat{Y}_{i}=\underset{(12.61)^{* *}}{748} \underset{(10.08)^{* * *}}{61.88} X_{i}$ & التكاليف الكلية بالجنيه بالأسعار الثابتة & 5 \\
\hline 0.90 & 0.95 & $\hat{Y}_{i}=\underset{(2.90)^{* * *}}{1538} \underset{(11.14)^{* * *}}{611.26} X_{i}$ & الإيراد الكلي بالجنيه بالأسعار الجارية & 6 \\
\hline 0.80 & 0.89 & $\hat{Y}_{i}=\underset{(2.67)^{* * *}}{1282}+\underset{(7.45)^{* * *}}{370.79} X_{i}$ & صافي العائد بالجنيه بالأسعار الجارية & 7 \\
\hline
\end{tabular}

المصدر:حسب من جدول (1)، (3) 
2530.7 جنيه/الفدان عام 2002 و أخذ في الارتفاع إلي أن

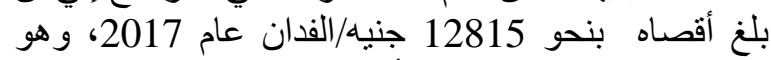
يزيد عن مثيله في سنة الأساس بنحو 10284.3 جنيه بنسبة 406.38\% أي أن إيراد الفدان لدحصول القدمح

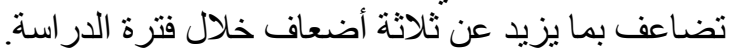

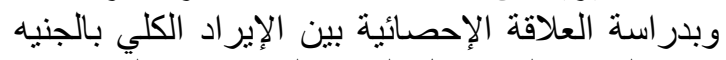

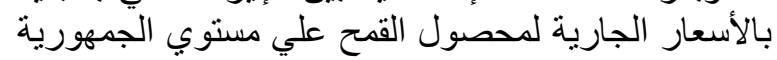

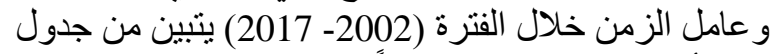

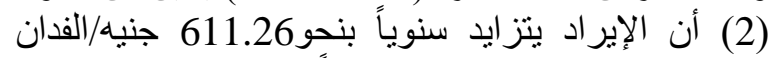

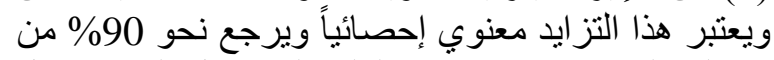

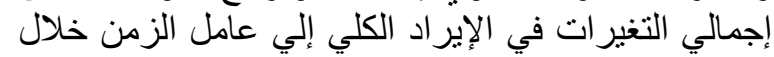

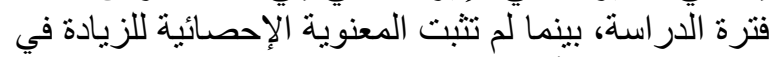
الإير اد الكلي بالأسعار الثابتة خلال فترة الثان الدراسة.

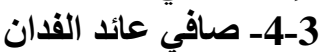
يعتبر صافي عائد الفدان من أهم العوامل الإن الاقتصادية

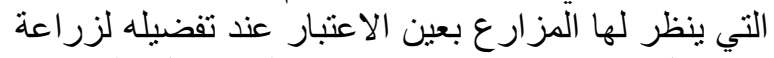

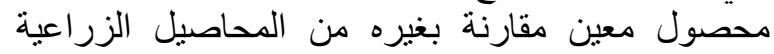

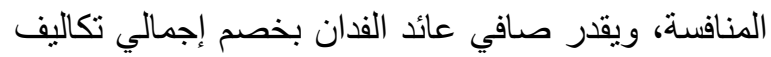

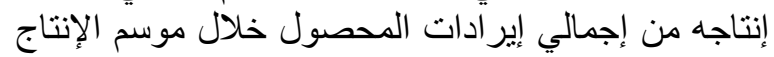

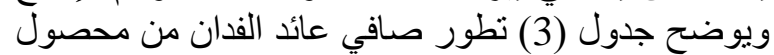
القمح بالجنيه علي مستوي الجمهورية خلال الفترة (2002-

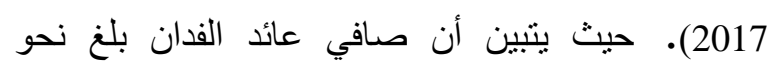

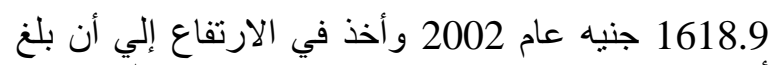

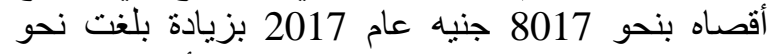

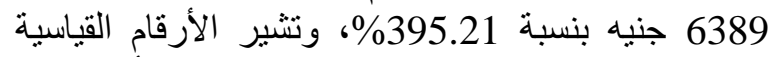

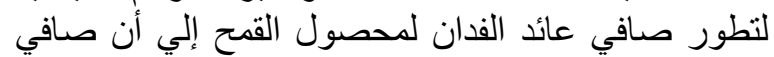

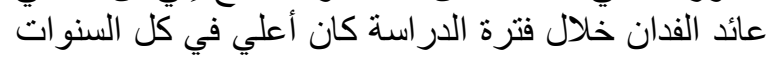

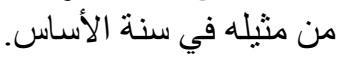
بيين جدول(3) العلاقة بين صافي فئي عائد الفدان بالجنيه

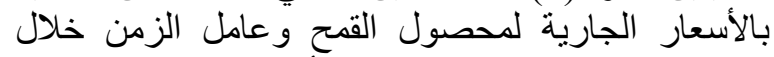

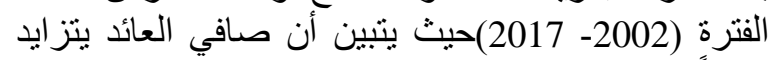

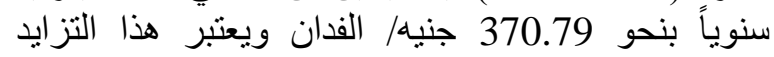

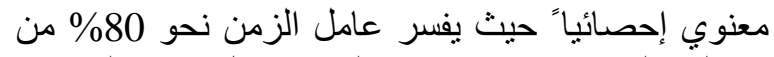

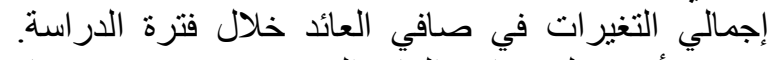

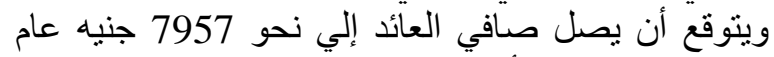
2019 إذا استمر تأثثر نفس العن العواند إمل المؤثرة علي سلسلة

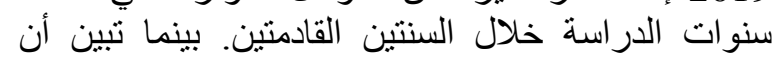

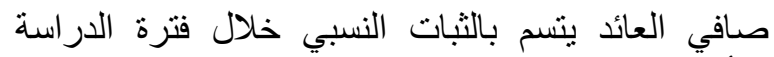

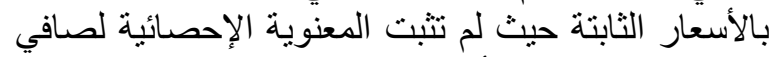

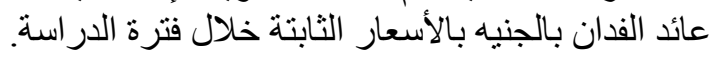

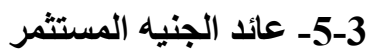

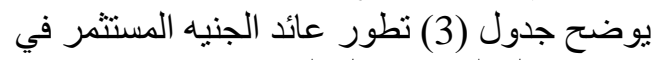

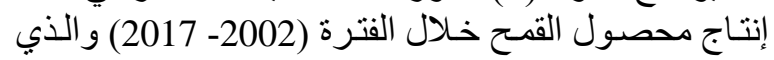
يعبر عن نسبة الإير اد الكلي للمحصول إلى اللي إجمالي تكاليف

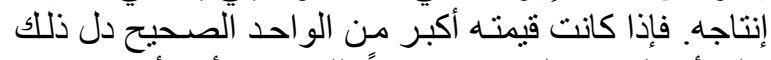

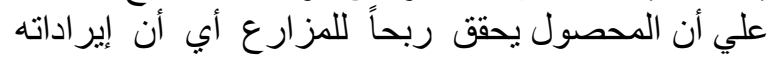

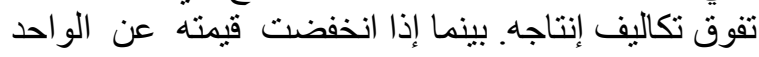

-1-3- السعر المزرعي

يوضح جدول (3) نطور المزيعر السعر المزرعي لمحصول

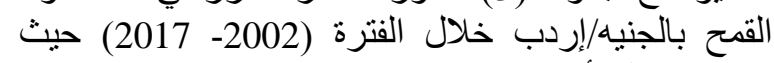

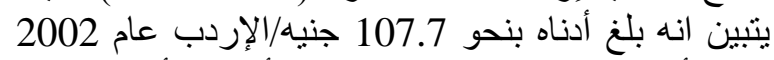
حيث أخذ في الارتفاع المستمر إلي أن بلغ الإنغ أقصاه بناه بنحو

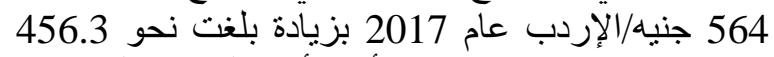

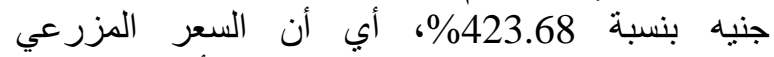
للمحصول تضاعف بما يزيد عن ثلاثة أضعاف أنعاف خلال

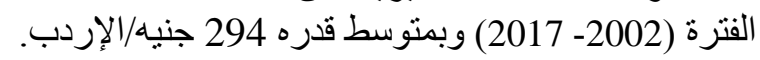

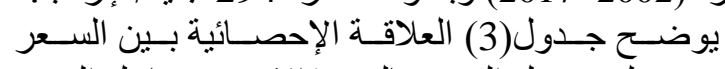

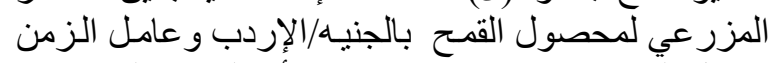

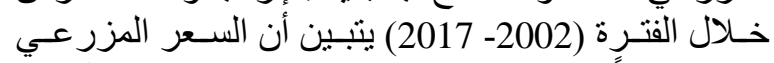
يتز ايد سنوياً بنحو 26.97 202.

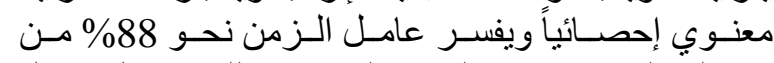

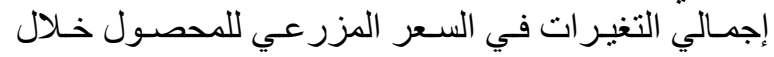

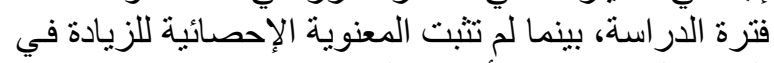

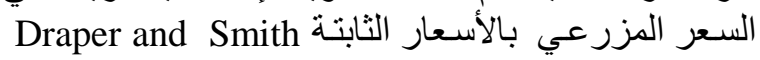

-2-3 - التكاليف الإنتاجية تمثل التكاليف الإلتنتاجية عاملاً مهماً في السياسة

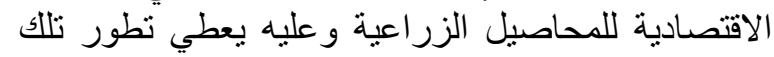

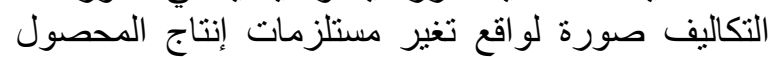

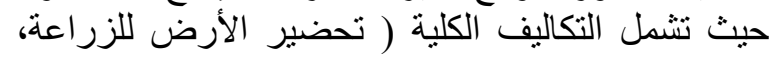

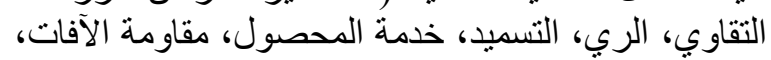
الحصأد، نقل المحصول، مصاري، خداريف أخري).

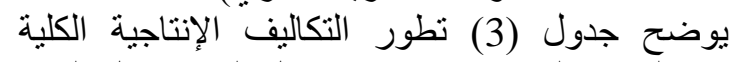
بالجنيه اللازمة لزراعة فدان بمحصول القمح خلال الفترة

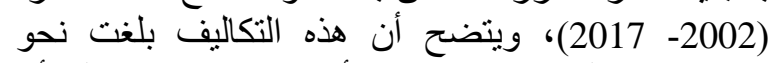

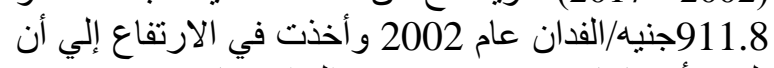

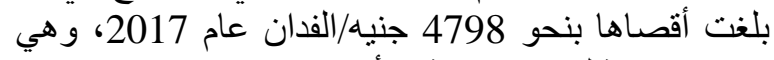
تزيد عن مثيلتها في سنة الأساس بنحو 3886.2 جنيه بنسبة 426.21\% أبي أن تكاليف إنتاج الفدان لمحصول بندان

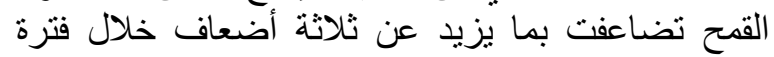

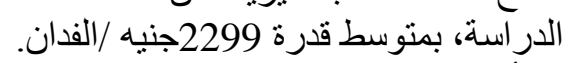
أظهرت نتائج جدول(2) العلاقة الإحصائية بين تكاليف

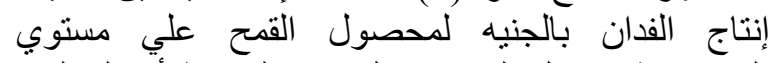

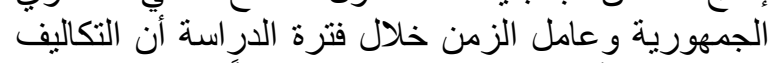

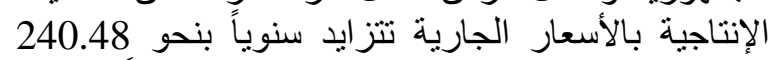

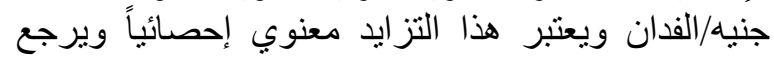
نحو 95\% من إجمالي التغيرات في تكاليف الإنتاج إلي التئ

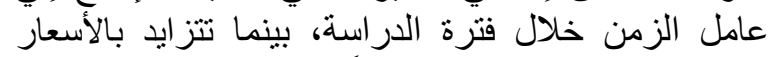

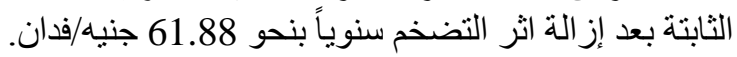

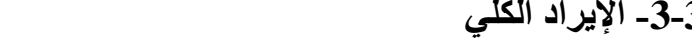
يمثل الإيراد ألكلي حاصل ضرب الإبل الإنتاج الكلي في

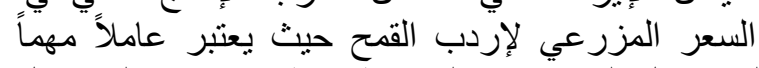

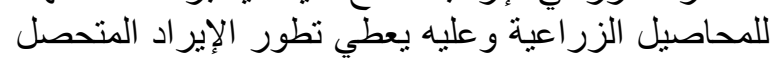

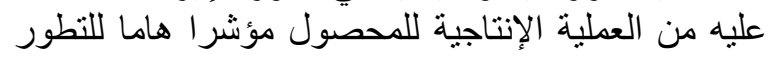

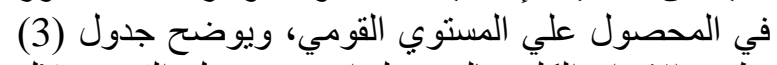
تظور الإيراد الكلي بالجنيه لفدان بمحصول المئول القمح خلال

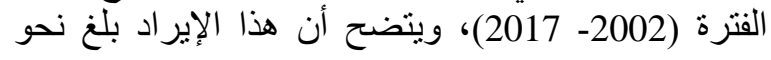


جدول (3) : تطور أهم المؤشرات الاقتصادية للقمح خلال الفترة (2002-2017).

\begin{tabular}{|c|c|c|c|c|c|c|c|c|c|c|c|c|c|}
\hline الجنيه & القياسب & صافي عائد & بالئا بالأل & القياسي & 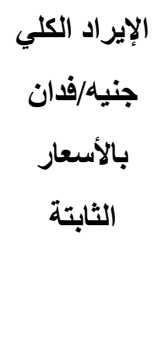 & جنالأليه/فدان & القياسي & 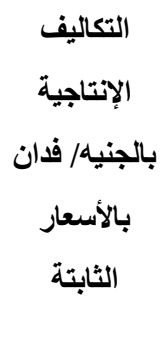 & بالجالإلتاجية & القياسي & بالجزال الإلبعر & 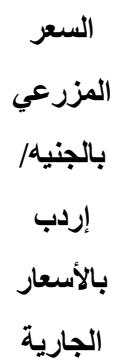 & السنة \\
\hline 2.78 & 100 & 1618 & 1618 & 100 & 2530.70 & 2530.7 & 100 & 911.80 & 911.8 & 100 & 107.70 & 107.7 & 2002 \\
\hline 2.70 & 106.24 & 1563.6 & 1720 & 107.91 & 2482.73 & 2731 & 110.88 & 919.09 & 1011 & 105.85 & 103.64 & 114 & 2003 \\
\hline 3.23 & 152.26 & 2143.5 & 2465 & 141.07 & 3104.35 & 3570 & 121.19 & 960.87 & 1105 & 139.2 & 130.43 & 150 & 2004 \\
\hline 3.41 & 171.97 & 2320.0 & 2784 & 155.57 & 3230.65 & 3937 & 126.45 & 960.83 & 1153 & 155.99 & 140.00 & 168 & 2005 \\
\hline 3.15 & 168.94 & 2205.7 & 2735 & 158.30 & 3280.83 & 4006 & 139.40 & 1025.00 & 1271 & 156.92 & 136.29 & 169 & 2006 \\
\hline 2.87 & 169.50 & 2002.9 & 2744 & 166.48 & 3075.18 & 4213 & 161.11 & 1072.26 & 1469 & 160.63 & 126.28 & 173 & 2007 \\
\hline 4.41 & 396.50 & 4685.4 & 6419 & 328.13 & 6061.31 & 8304 & 206.73 & 1375.91 & 1885 & 355.62 & 279.56 & 383 & 2008 \\
\hline 2.82 & 225.21 & 2083.4 & 3646 & 223.22 & 3228.00 & 5649 & 219.68 & 1144.57 & 2003 & 224.70 & 138.29 & 242 & 2009 \\
\hline 2.67 & 218.79 & 1854.5 & 3542 & 223.53 & 2961.78 & 5657 & 231.96 & 1107.33 & 2115 & 252.55 & 142.41 & 272 & 2010 \\
\hline 3.26 & 340.35 & 2884.8 & 5510 & 314.26 & 4163.87 & 7953 & 267.93 & 1279.06 & 2443 & 326.83 & 184.29 & 352 & 2011 \\
\hline 3.24 & 375.01 & 3195.3 & 6071 & 347.06 & 4622.63 & 8783 & 297.43 & 1427.37 & 2712 & 350.97 & 198.95 & 378 & 2012 \\
\hline 2.97 & 372.29 & 2883.7 & 6027 & 358.87 & 4345.45 & 9082 & 335.05 & 1461.72 & 3055 & 359.33 & 185.17 & 387 & 2013 \\
\hline 2.76 & $\mathbf{3 6 7 . 3 5}$ & 2715.5 & 5947 & 368.20 & 4254.79 & 9318 & 369.71 & 1539.27 & 3371 & 381.62 & 187.67 & 411 & 2014 \\
\hline 2.63 & 366.17 & 2577.4 & 5928 & 378.08 & 4160.00 & 9568 & 399.21 & 1582.61 & 3640 & 383.47 & 179.57 & 413 & 2015 \\
\hline 2.50 & 356.91 & 2458.7 & 5778 & 380.41 & 4096.60 & 9627 & 422.13 & 1637.87 & 3849 & 386.26 & 177.02 & 416 & 2016 \\
\hline 2.67 & 495.21 & 3326.6 & 8017 & 506.38 & 5317.43 & 12815 & 526.21 & 1990.87 & 4798 & 523.68 & 234.02 & 564 & 2017 \\
\hline 3.00 & 273.92 & 2532.5 & 4434 & 266.09 & 3807.3 & 6734 & 252.19 & 1274.8 & 2299 & 272.7 & 165.7 & 294 & المتوسط \\
\hline
\end{tabular}


تكاليف إنتاجية بنحو 3602 جنيه للموسم الأول 3650 جنيه للموسم الثاني.

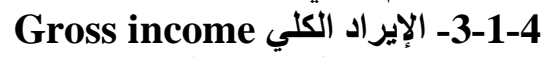

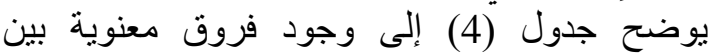

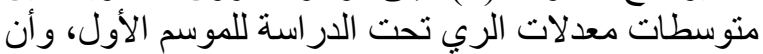
معاملة الري الثنانية حققت أعلى إيراد بنحو 10023.22 جنيه، في حين حققت المعاملة الأولي أدنى إيراد إدباد بنحو

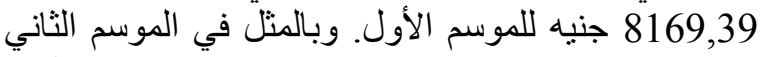
تبين وجود فروق معنوية بين منوسطات معدلات الرئ الري الري الريان حققت معاملة الري الثانية أعلى إير اد بنحو في حين حققت المعاملة الأولي أدنى إيرادئ ادئ بنحو 8317 فنيه.

Net return -4-4 -4 صافي العائد

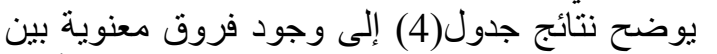

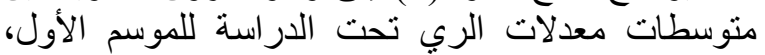

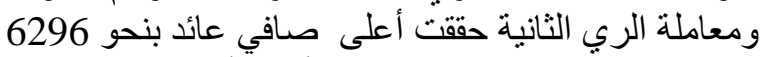

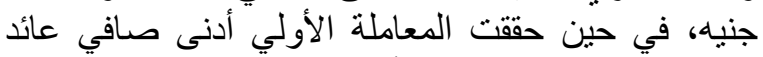

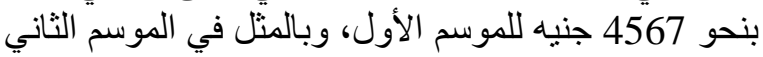

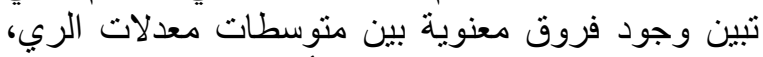

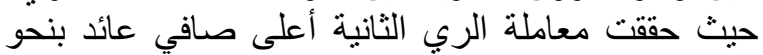

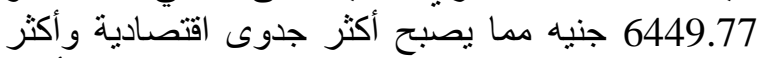

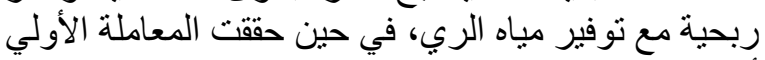
أدنى صافي عائد بنحو -5-1-4 عائد الجنيه المستثر

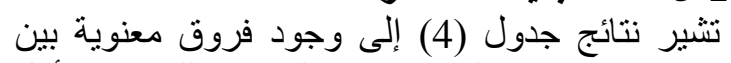

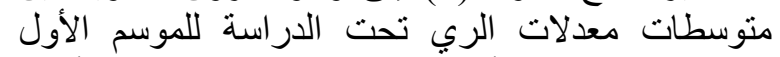

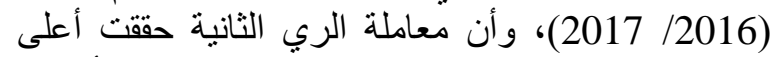

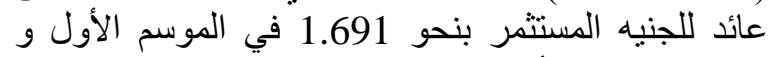

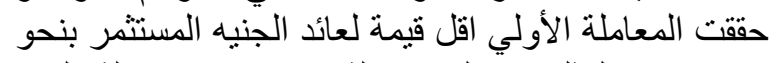

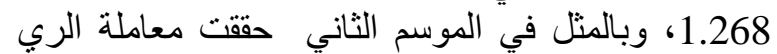
الثانية حققت أعلى عائد للجنيه المستثمر بنحو 1.713 مها

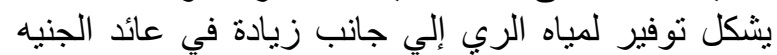
المستثمر و حققت المعاملة الأولي اقل قيمة لئل لعائد الجنيه المستثمر بنحو 1.280. 2-4- التقييم الاقتصادي لتأثير التراكيب الوراثية لقمح الخبز

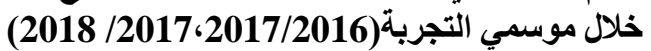

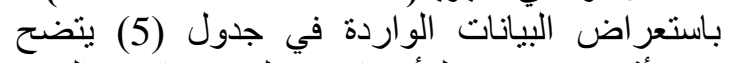

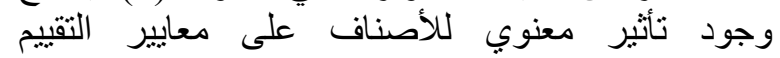
الاقتصادي و هي: - الأير

Grain yield ( Ard/fed) الإنتاجية الفدانية

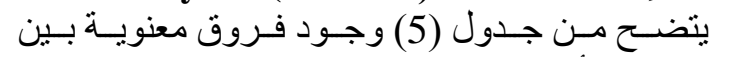

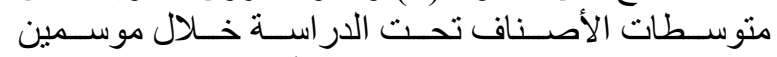

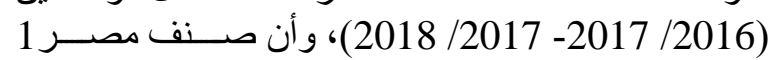
حقق أعلى إنتاجية بنحو 23.508 إردب/ في فدان، يليه سـلالة

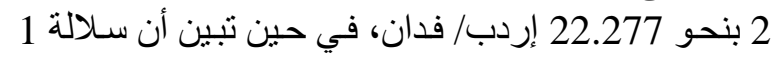

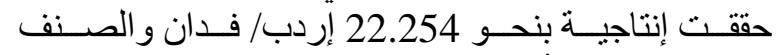

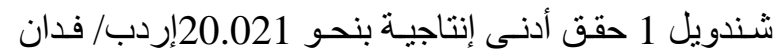

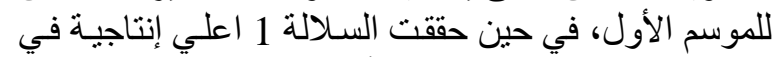

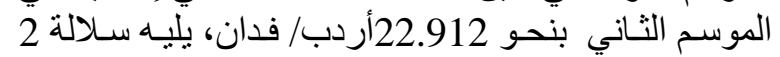

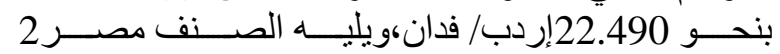

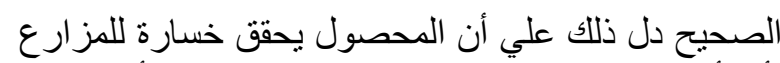

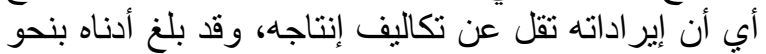

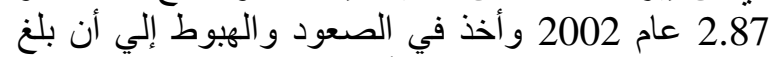

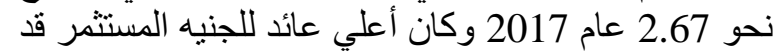

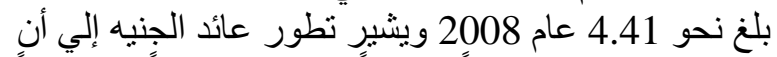
المحصول يحقق عائداً مجزياً ويعتبر مربحاً اقتصنادياً

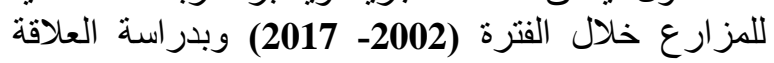
الإحصائية بين عائد الجنيه المستثمر في إنتاج محصول المبرل

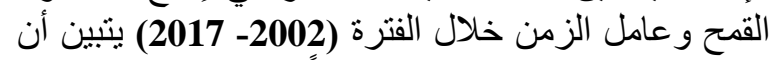

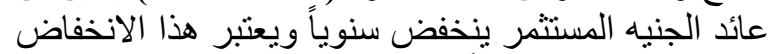

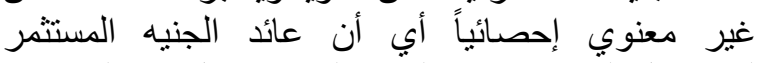

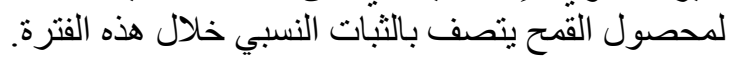

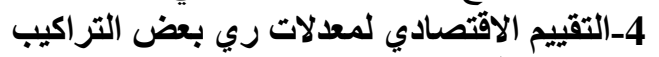

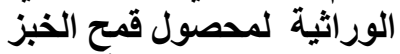

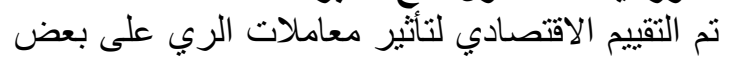

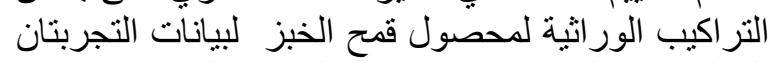

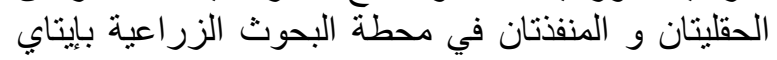

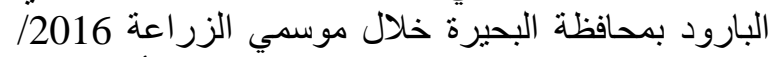

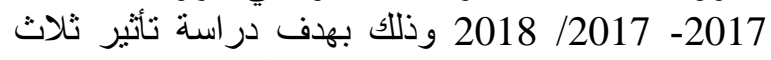

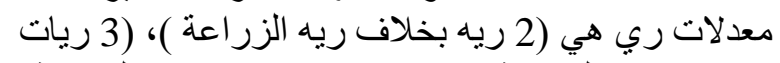

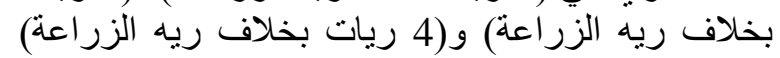

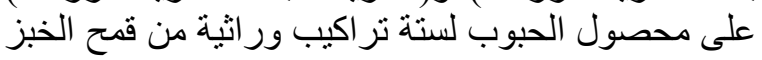

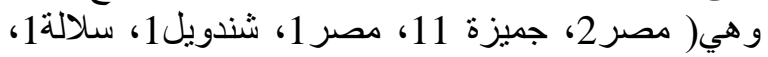

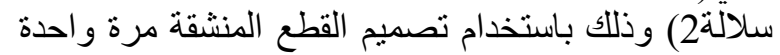

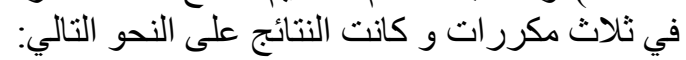

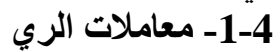

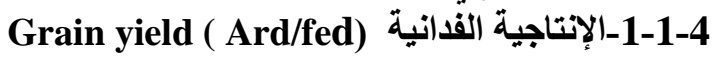

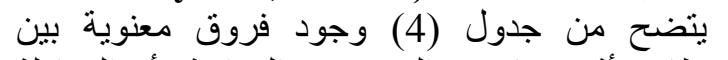

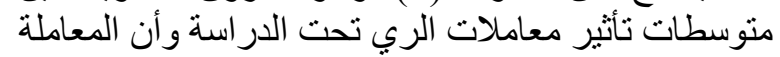

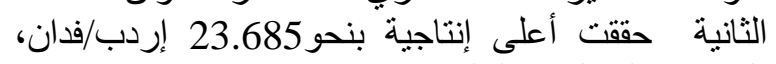

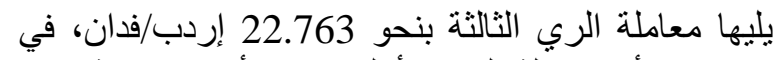

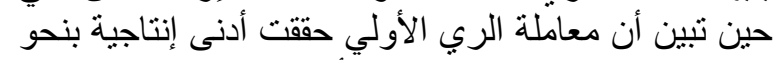

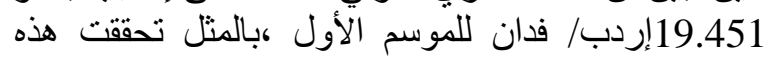

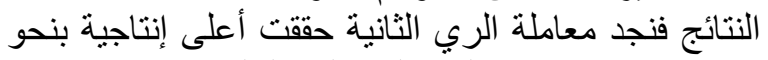

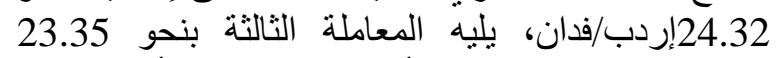
إردب/فدان، في حين تبين أن معاملة الري الرئة الأولي حققت

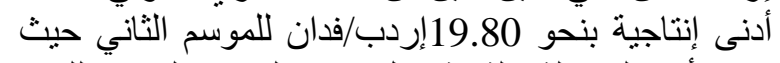

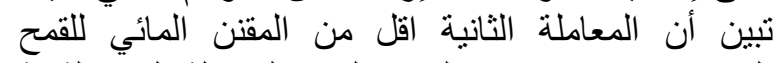

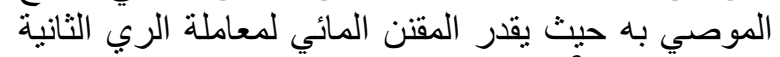

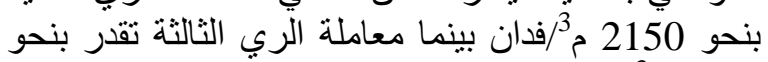

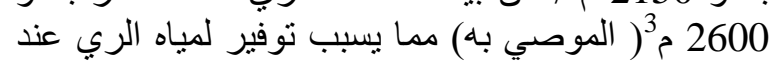

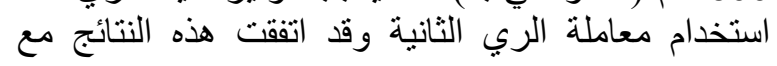

.Sarwar et al. (2010)

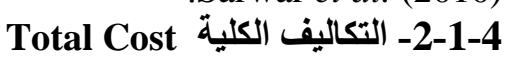
يتبين من جدول (4) عدم وجود فروق الكالية معندوية بين

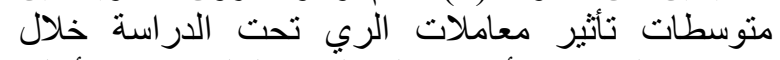

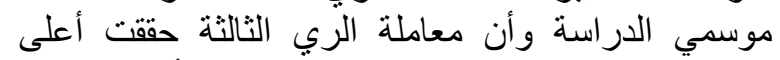

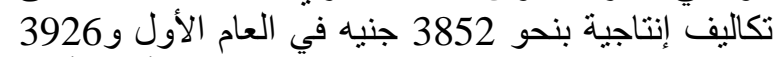
جنيه للعام الثاني. في حين حققت المعاملة الأولي أدنى 


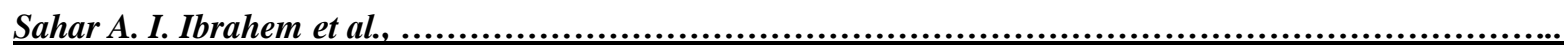

Gross income 3-2-4 الإيراد الكلي (5) بوني يشير جدول (5) الإيرالى وجود فروق معنوية بين

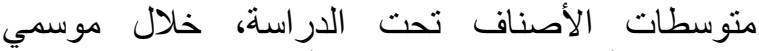
الدراسة، و أن صنف مصر 1 حقق أعلى إير اد بنحو جنيه/ فدان، يليه سلالة 2 بنحو 9356جنيه إنيه/فدان، في حين إني تبين أن سلالة1 حقت إئ إيراد بنحو 9304 جنيه/فيدان

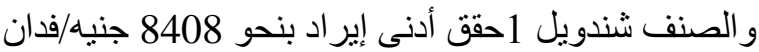

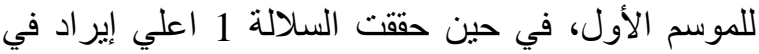

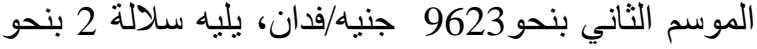
9446 جنيه/فدان، ويليه الصنف مصر2 بنحو 9443

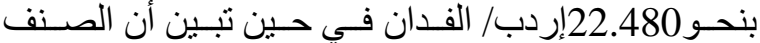

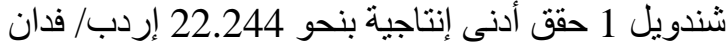
للموسم الثاني، وقد اتفقت هذه النتائج مع كل من محمد الند

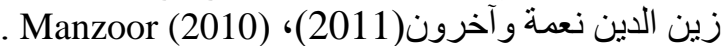

Total Cost التكاليف الكلية يتبين من جدول (5) عدم وجود فروق معنوية بين الأين متوسطات الأصناف تحت الدراسة من حيث التكان التكاليف

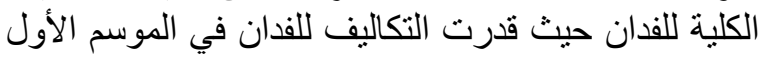
بنحو 3780 جنيه/الفدان وقدرت تكاليف الفالف الموسم الثاني بنحو 3650 جنيه/الفدان.

جدول (4): متوسطات تأثير معدلات الري القمح الخبز على بعض معالم التقييم الاقتصادي.

\begin{tabular}{|c|c|c|c|c|c|c|}
\hline الجنيه & بالجنيه/فافي العائد & بالجنيا/فدان & بالجنيان/فذان & بالإلإردبة|فدان & معدلات الري & العام \\
\hline 1.268 & 4567 & 8169 & 3602 & 19.451 & معاملة الري الأولي & \multirow{4}{*}{$\begin{array}{l}\text { 룽 } \\
\frac{1}{1} \\
\frac{1}{0}\end{array}$} \\
\hline 1.691 & 6296 & 10023 & 3727 & 23.865 & معاملة الري الثانية & \\
\hline 1.482 & 5700 & 9560 & 3852 & 22.763 & معاملة الري الثالثة & \\
\hline 0.106 & 416.1 & 124.8 & N.S. & 0.988 & L.S.D (0.05) & \\
\hline 1.280 & 4667 & 8317 & 3650 & 19.80 & معاملة الري الاولي & \multirow{4}{*}{ 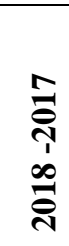 } \\
\hline 1.713 & 6449 & 10213 & 3764 & 24.32 & معاملة الري الثانية & \\
\hline 1.498 & 5882 & 9808 & 3926 & 23.35 & معاملة الري الثالثة & \\
\hline 0.143 & 220.9 & 220.9 & N.S. & 0.526 & L.S.D (0.05) & \\
\hline
\end{tabular}

المصدر: نتائج تحليل البيانات المجمعة من التجارب المنفذة بايتاي البارود، البحيرة.

جلول (5): متوسطات تأثير التراكيب الوراثية لقدح الخبز على بعض معالم التقييم الاقتصادي.

\begin{tabular}{|c|c|c|c|c|c|c|}
\hline عائد الجنيه & بالجنيه/فافي العائد & بالجنيه/الإيراد & بالجنيه/فاليفان & بالإردب/فذان & التراكيب الوراثية & 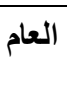 \\
\hline 1.484 & 5542 & 9269 & 3727 & 22.07 & مصر 2 & \multirow{7}{*}{ 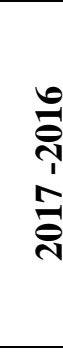 } \\
\hline 1.491 & 5566 & 9293 & 3727 & 22.128 & جميزة11 & \\
\hline 1.653 & 6146 & 9873 & 3727 & 23.508 & مصر 1 & \\
\hline 1.254 & 4681 & 8408 & 3727 & 20.021 & شندويل1 & \\
\hline 1.496 & 5577 & 9304 & 3727 & 22.154 & سلالة 1 & \\
\hline 1.506 & 5629 & 9356 & 3727 & 22.277 & سلالة2 & \\
\hline 0.126 & 466.9 & 697.4 & N.S. & 1.107 & L.S.D (0.05) & \\
\hline 1.497 & 5663 & 9443 & 3780 & 22.480 & مصر 2 & \multirow{7}{*}{ 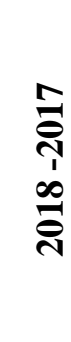 } \\
\hline 1.494 & 5660 & 9440 & 3780 & 22.477 & جميزة11 & \\
\hline 1.480 & 5603 & 9383 & 3780 & 22.341 & مصر1 & \\
\hline 1.460 & 5562 & 9342 & 3780 & 22.244 & شندويل1 & \\
\hline 1.540 & 5843 & 9623 & 3780 & 22.912 & سلالة 1 & \\
\hline 1.500 & 5666 & 9446 & 3780 & 22.490 & سلالة2 & \\
\hline 0.081 & 320.4 & 320.4 & N.S. & 0.845 & L.S.D (0.05) & \\
\hline
\end{tabular}


تبين خلال الموسم الثاني أن هناك فروق معنوية بين

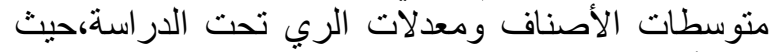
تبين أن سلالة 1 +معاملة الري الثانية (4 ريات الريات) حققت

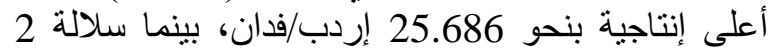
+معاملة الري الثانية (4ريات) حققت أعلى إنتاجية بنحو

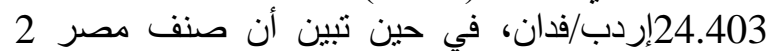
+معاملة الري الثانية (4 ريات) حقق أعلى إنى إنتاجية بنحو

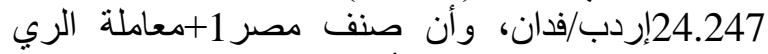

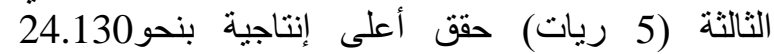

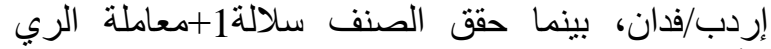
الأولي (3 ريات) اقل إنتاجية بنحو 19.367إردب/فلفان

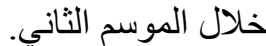

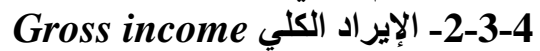
يشير جدول (6) إلى وجود فروق معنوية في الإير اد الادير

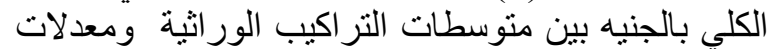

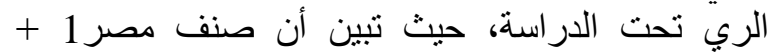

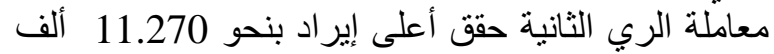

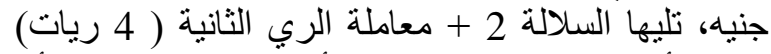

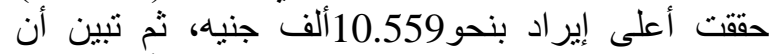
صنف جميزة 11 +معاملة الري الثنانية حقق أعلى إيراد

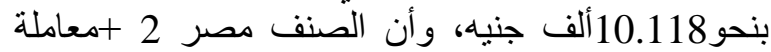

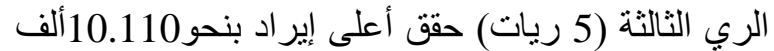

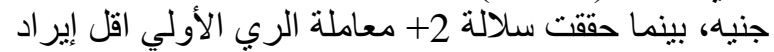
بنحو 7.733 ألف جنية خلال الموسم الأول.

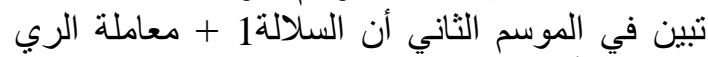
الثانية حققت أعلى إيراد حيث قدر الإيراد الكيث الكلي بنحو

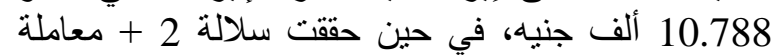
الري الثانية أعلى إيراد بنحو صنف مصر 2 + معاملة الري الثنانية حقق اعلي إيراد

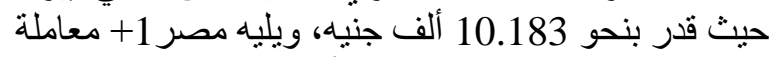
الري الثانية بنحو 10.134 ألف جنيه، بينما حققت سلالة + معاملة الري الأول اقل قيمة للإير اد بنحو 8.134

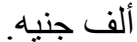

Net return -3-3-4

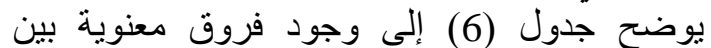

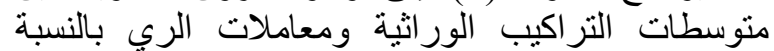

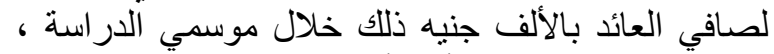

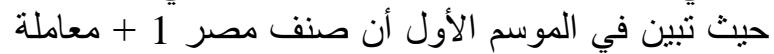
الري الثانية حقى أعلى صافي عائد بنحو التحل

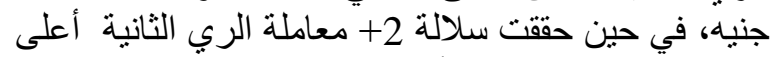

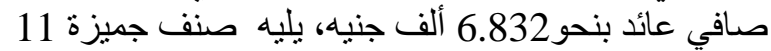
+ معاملة الري الثانية حقق أعلى صافي عائد

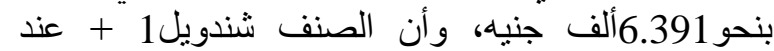
معاملة الري الأولي حققت أقل صافي عائد بنحو 3.919

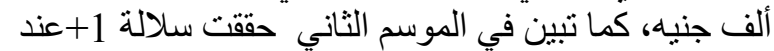
معاملة الري الثانية أعلى صافي الثي عائد بنحو 7.024 ألف الف الفي

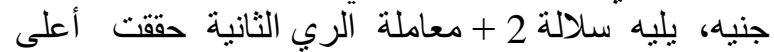

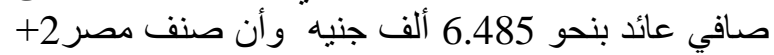

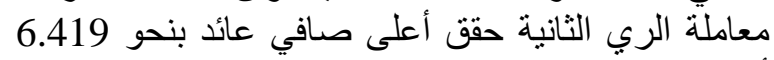
ألف جنيه، يلّيه الصنف شندية الصنديل 1 + معاملة الري الثانية
جنيه/الفدان في حين تبين أن الصنف شندويل 1 حقق أدنى

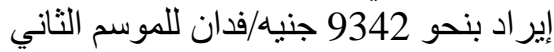

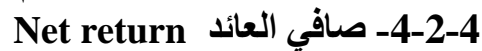

يبين جدول (5) وجود فروق معنوية بين منوسطات الأصناف تحت الدر اسة، خلال موسمي الدر اسة، و وأظهرت

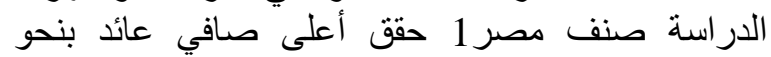

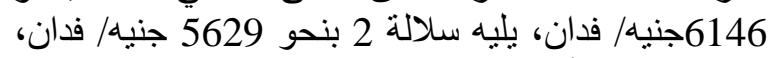

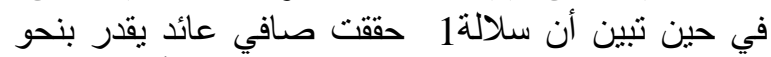

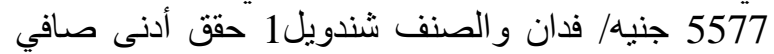

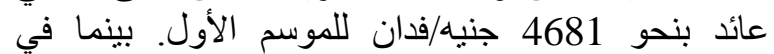

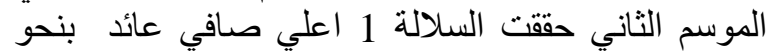

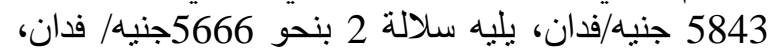

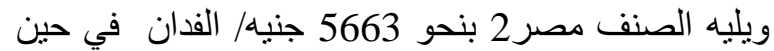
تبين أن الصنف شندويل1 الصن حقق أدنى صافي عائد بنحو

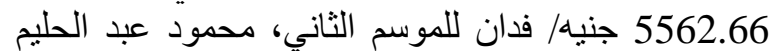

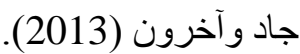
- 5-2-4 - عائد الجنيه المستثمر (2013 يبين جدول(5) وجواليه المود فروق معنوية بين منوسطات

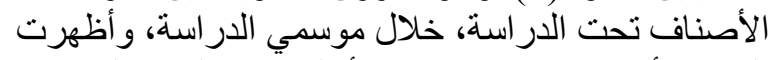

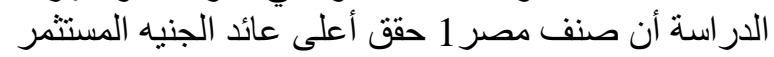

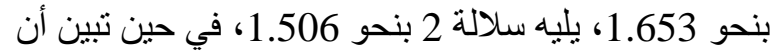

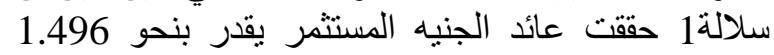

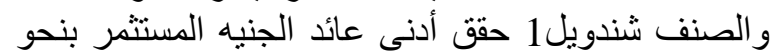

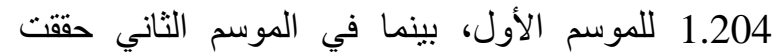
السلالة 1 اعلي عائد الجنيه المستثمر بنحو المئم 1.54، يليه

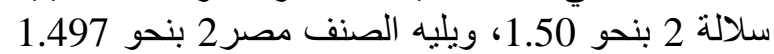
في حين تبين أن الصنف شندويل 1.56 احقق أدنى عائد الجنيه

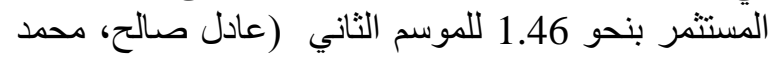

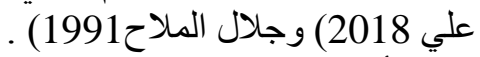

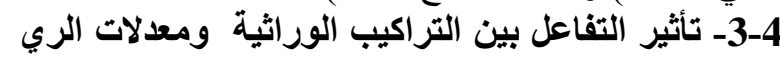

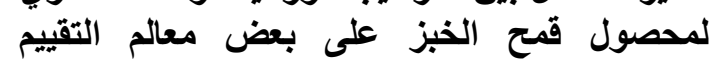

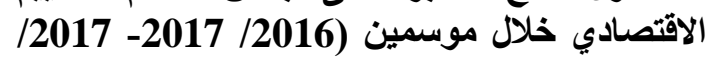

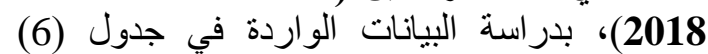

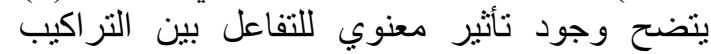

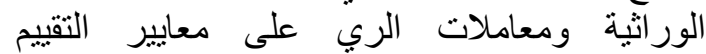

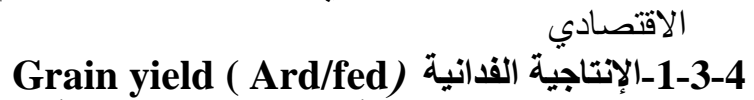
بتضح من جدول (6) أن النية الإنتاجية الفدانية تأثرت

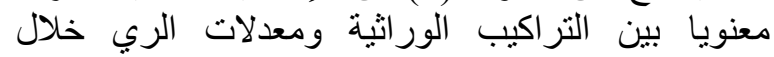

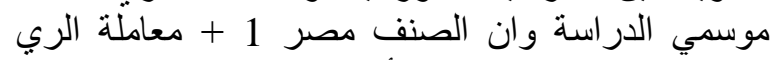

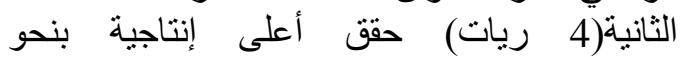
26.833إردب/فدان، بينما سلالة 2 + معاملة الربي الثانية

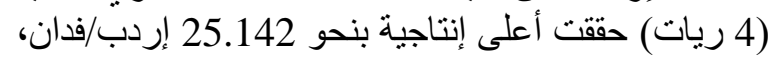
في حين تبين أن صنف جميزة 11 أنفي + معاملة الري

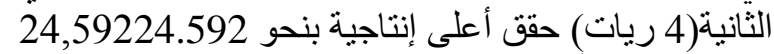

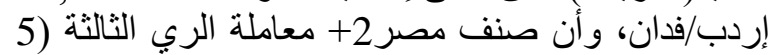

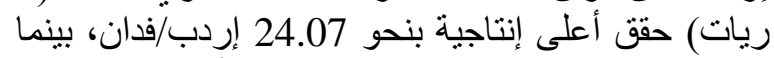

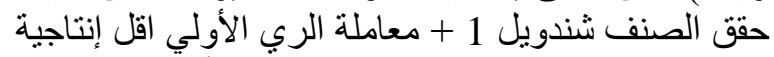
بنحو 17.908 بإردب/فدان خلال الموسم الأول .al.(2017) 
جدول (6): متوسطات تأثير التفاعل بين التراكيب الوراثية ومعدلات الري لقمح الخبز على بعض معالم التقييم الاقتصادي.

\begin{tabular}{|c|c|c|c|c|c|c|c|}
\hline \multirow{2}{*}{ المنتيه } & \multirow{2}{*}{ جنيه/فافئد } & \multirow[b]{2}{*}{ جنيه/فدان } & \multirow[b]{2}{*}{ جنيه/فدان } & \multirow{2}{*}{ بالإردب/فدان } & \multicolumn{2}{|c|}{ المعاملات } & \multirow[b]{2}{*}{ العام } \\
\hline & & & & & التراثية & معاملات الري & \\
\hline 1.28 & 4613 & 8215 & 3602 & 19.561 & مصر 2 & \multirow{6}{*}{ معاملة الري } & \multirow{19}{*}{ 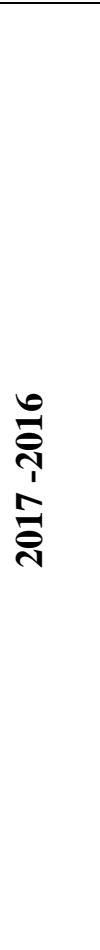 } \\
\hline 1.26 & 4532 & 8134 & 3602 & 19.366 & جميزة11 & & \\
\hline 1.49 & 5340 & 8942 & 3602 & 21.291 & مصر 1 & & \\
\hline 1.59 & 3919 & 7521 & 3602 & 17.908 & شندويل1 & & \\
\hline 1.35 & 4866 & 8468 & 3602 & 20.164 & سلالة 1 & & \\
\hline 1.15 & 4131 & 7733 & 3602 & 18.414 & سلادة2 & & \\
\hline 1.55 & 5754 & 9481 & 3727 & 22.575 & مصر 2 & \multirow{6}{*}{ معاملة الري } & \\
\hline 1.71 & 6391 & 10118 & 3727 & 24.592 & جميزة11 & & \\
\hline 2.03 & 7543 & 11270 & 3727 & 26.833 & مصر 1 & & \\
\hline 1.40 & 5215 & 8942 & 3727 & 21.292 & شندويل1 & & \\
\hline 1.62 & 6040 & 9767 & 3727 & 23.256 & سلالة & & \\
\hline 1.83 & 6832 & 10559 & 3727 & 25.142 & سلالة2 & & \\
\hline 1.63 & 6258 & 10110 & 3852 & 24.072 & مصر 2 & \multirow{6}{*}{ معاملة الري } & \\
\hline 1.50 & 5776 & 9628 & 3852 & 22.925 & جميزة11 & & \\
\hline 1.45 & 5556 & 9408 & 3852 & 22.400 & مصر 1 & & \\
\hline 1.28 & 4910 & 8762 & 3852 & 20.864 & شندويل1 & & \\
\hline 1.51 & 5325 & 9677 & 3852 & 23.041 & سلالة & & \\
\hline 1.54 & 5923 & 9775 & 3852 & 23.275 & سلادة2 & & \\
\hline 0.12 & 569.4 & 805.2 & 1.917 & 1.88 & \multicolumn{2}{|c|}{ L.S.D.(0.05) } & \\
\hline 1.34 & 4900 & 8550 & 3650 & 20.35 & مصر 2 & \multirow{6}{*}{ معاملة الري } & \multirow{19}{*}{ 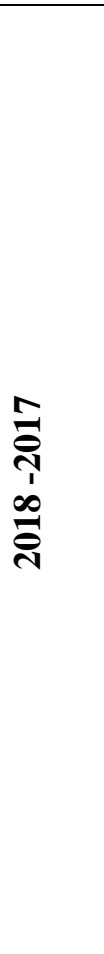 } \\
\hline 1.27 & 4631 & 8281 & 3650 & 19.717 & جميزة11 & & \\
\hline 1.26 & 4582 & 8232 & 3650 & 19.60 & مصر 1 & & \\
\hline 1.27 & 4631 & 8281 & 3650 & 19.717 & شندويل1 & & \\
\hline 1.23 & 4484 & 8134 & 3650 & 19.367 & سلالة 1 & & \\
\hline 1.31 & 4778 & 8428 & 3650 & 20.067 & سلالة2 & & \\
\hline 1.71 & 6419 & 10183 & 3764 & 24.247 & مصر 2 & \multirow{6}{*}{ معاملة الري } & \\
\hline 1.64 & 6191 & 9955 & 3764 & 23.700 & جميزة11 & & \\
\hline 1.69 & 6370 & 10134 & 3764 & 24.130 & مصر 1 & & \\
\hline 1.65 & 6207 & 9971 & 3764 & 23.741 & شندويل1 & & \\
\hline 1.86 & 7024 & 10788 & 3764 & 25.686 & سلالة 1 & & \\
\hline 1.72 & 6485 & 10299 & 3764 & 24.403 & سلالة2 & & \\
\hline 1.44 & 5669 & 9595 & 3926 & 22.847 & مصر 2 & \multirow{6}{*}{ معاملة الري } & \\
\hline 1.57 & 6159 & 10085 & 3926 & 24.014 & جميزة11 & & \\
\hline 1.49 & 5857 & 9783 & 3926 & 23.294 & مصر 1 & & \\
\hline 1.48 & 5849 & 9775 & 3926 & 23.274 & شندويل1 & & \\
\hline 1.53 & 6021 & 9947 & 3926 & 23.683 & سلالة 1 & & \\
\hline 1.46 & 5735 & 9661 & 3926 & 23.001 & سلالة2 & & \\
\hline 0.14 & 555 & 555 & N.S & 2.0591 & \multicolumn{2}{|c|}{ L.S.D.(0.05) } & \\
\hline
\end{tabular}


وزارة الزراعة واستصلاح الأراضي، قطاع الثئون

الاقتصادية، نشرة الإحصاءات الإنهات الزراعية، أعداد

مختلفة.

نشرة الميزان الغذائي، (2016) ـ وزارة الأنية الزراعة

و واستصلاح الأر اضي، قطاع الثنئون الاقتصنادية.

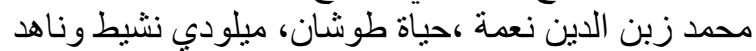

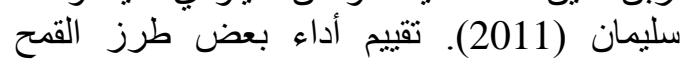

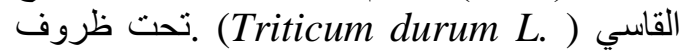

العجز المائي اعتمادا على بعض المؤشرات الثنكلية

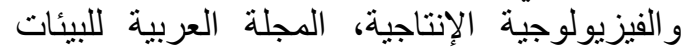

الجافة 4(1): 4-18 سوريا.

Draper N. R. and Smith H. (1966). Applied regression analysis .John Wily and Sons, Jnc.N.Y.USA. : 397-402

Gomez K. A. and Gomez A. A. (1984), Statistical procedures for agricultural research, $2^{\text {nd }}$ ed., John Wiley and Sons, New York,U S A.

Harb O.M., Abd El Hay G.H., Hagar M.A. and Abou El Enin M.M. (2017). Evaluation of Irrigation Scheduling Program and Wheat Yield Response in Egyptian Sandy Soil Conditions, Adv Crop Sci Tech,Volume 5 . Issue 5:2.

Manzoor H. (2010). New wheat variety “ Fareed-06" for irrigated areas of Punjab, Pakistan. Pa. k. J. Bot., 42(5): 3285-3297.

Sarwar N., Maqsood M., Mubeek K., Shelld M., Bbuller M.S., Qanar R.and Akbar N. (2010). Effect of different levels of irrigation on yield and yield components of wheat cultivars, Pak. J. Agri. Sci, 47(3):371-374.

Snedecor G.W. and Cochran W.G. (1988). Statistical methods , $7^{\text {th }}$ ed. , lowa State Univ. press, Ames, Iowa. USA.
بنحو 6.207 ألف جنيه، بينما حقق سلالة 1 + معاملة الري الأولي اقل صافي عائد بنحو 4.484 ألف جنئ الفيه. 4-4-4-4 عائد الجنية المستثمر

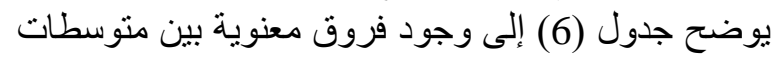
التراكيب الور اثثية ومعدلات التقات التقاوي بالنسبة لعائد الجنيه

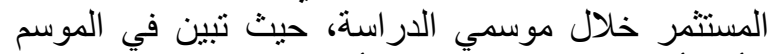

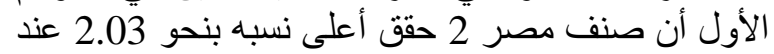

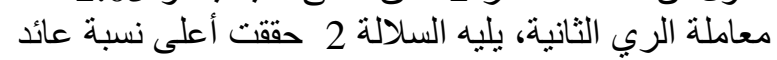

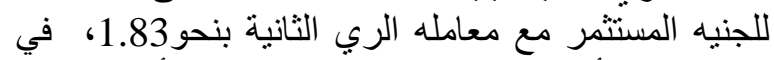

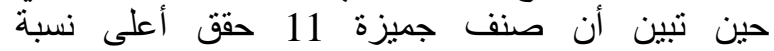

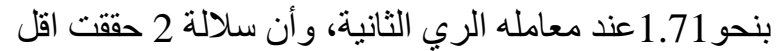

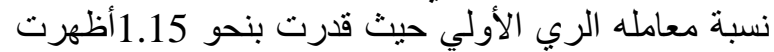

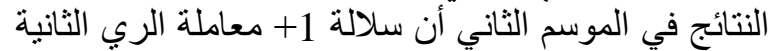

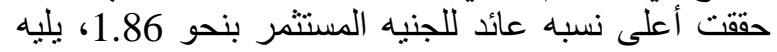
السلالة 2 + عند معاملة الري الثانية حققت أعلى نسبة

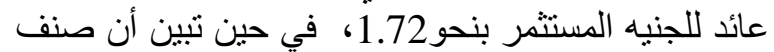

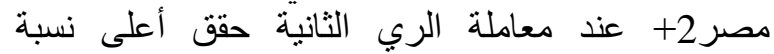
بنحو 1.71، يليه مصر 1 + + معاملة الري الثانية بنحو الرئ

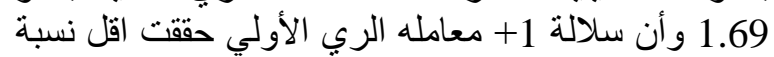

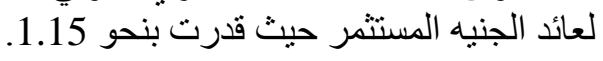

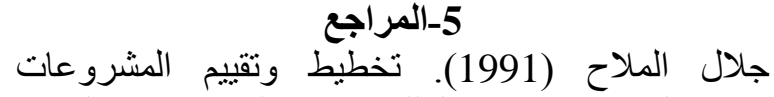
الزراعية جامعة الملك سعود، القصيم، دار المريخ المريخ للنشر ص ص ص 130- 135.

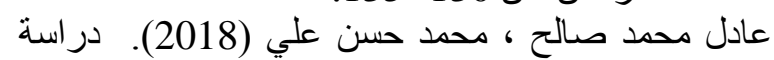
اقتصادية تحليلية لتخفيض الفجوة القمحية في مصر.

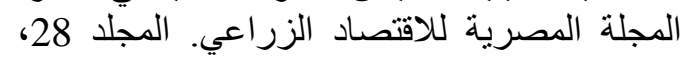

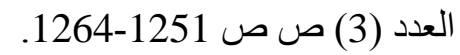

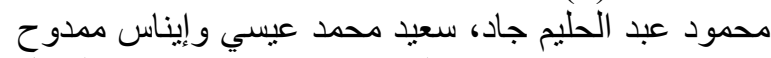

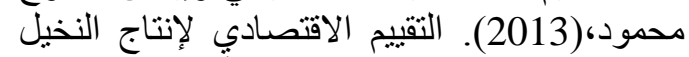

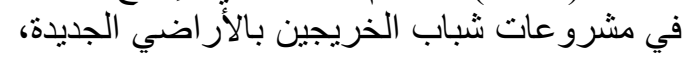

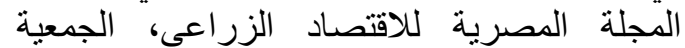
الاقتصادية للاقتصاد الزراعي،المجلد (21)، العدداء العدية

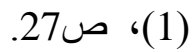

